\title{
AAATE Newsletter, Spring 2003
}

\section{FROM THE EDITOR}

Lawrence Normielnormie@jdc.org.il

About a week ago I attended a talk by a local intellectual, whose life's work, until about nine years ago, had been in the field of special education. He is at an advanced stage of ALS (amyotrophic lateral sclerosis) also know as Lou Gehrig's, disease, being artificially respirated and tube-fed. His talk was rather eclectic, but the underpinning theme was a critique on the subjectivity of "quality of life".

Despite having encountered it so many times before with people having severe disability, I could not help but be awed by this individual's incredible optimism and joie de vivre. With regard to many people with disabilities (at least in my own experience) psychological well-being rarely is perceived in proportion to the severity of disability.

One might argue that people with an innate positive attitude to life will maintain this regardless of their circumstances. I do not doubt that; though I should add that, at the very start of his talk, our lecturer stated: "these last nine years are the best years of my life".

Whatever the explanation, many people with ALS and other conditions resulting in profound disability, nevertheless are able successfully to transcend their physical limitations (no small part being played by AT) and lead their lives full to the brim. This confers an important message to all of us.

\section{PRESIDENT'S MESSAGE}

\section{Renzo Andrich renzo.andrich@siva.it}

Dear AAATE Members, the European Year of People with Disabilities has taken wing in all EU Countries, and we know of many AAATE members having a role in national initiatives. It is a unique opportunity to disseminate awareness of the role today's technology can play for increasing quality of life and overcome barriers to full participation in society. In relation to that, the AAATE Dublin 2003 Conference will be a major event. The Call for Papers was quite successful: 240 abstracts were received and, as I write, the review process has been completed and the requests for full papers have been sent out to the selected authors.

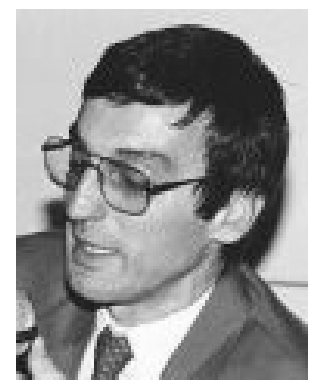

The Conference programme is in advanced preparation stage. Especially, we warmly hope the EC Commissioners Mr Erkki Liikanen (Enterprise and Information Society) and Ms Anna Diamantopoulou (Employment and Social Affairs) will be able to confirm their participation and offer their views in the Conference. In the contacts we had so far we had the opportunity to appreciate their interest and commitment in the Assistive Technology field.

While we are preparing ourselves for Dublin, we must be far-sighted and look ahead at the 2005 Conference. A Call for Bids was issued on January 31 to all Members, so we hope to receive several good candidacies before the May 31st deadline. Those who are interested are warmly invited to act as quickly as they can.

An important achievement the Board was able to carry out in its first 2003 meeting was the establishment of a networking / communication policy that will guide the AAATE initiatives for the time being. Some details are provided inside. A re-designed website offering a new set of services will be one milestone of such policy. To this end, a tender was sent out to all members on February 24 inviting to candidate for the management and editorial responsibility of the $A A A T E$ website. Deadline is again May 31st, however, for the website the Board will strive to have the bid evalua- 
tion completed and this task assigned before June so as to have the new website operational at the time of the Conference.

In order to have the "three pillars" of our publication policy well coordinated - the Journal "Technology and Disability", the Newsletter, and the Website - the publication committee was reshaped in such a way to have their three Editors communicating and working in synergy.

Well, the overall feeling is that this year seems quite promising for the Assistive Technology field and for our Association. We often happen to experience - in these times - how it is important for AAATE to exist and have visibility. And we are grateful to all Members who offer their expertise and their voluntary commitment, thus allowing for AAATE to exist, develop and contribute to the advancement of AT.

\section{NATIONAL NEWS}

\section{Reports from AAATE national contacts}

\section{Norway}

Erland Winterberg EWI@hmi.dk

\section{NAT-C - Nordic Assistive Technology Conference}

The conference is going to be held on the 19th20th May 2003 in Bella Centret in Copenhagen. The topic of the conference is Assistive Technology and Equal Opportunities with the following sub topics: 1) Arrangement of AT 2) Results and documentation / outcome and 3) AT - focus on product use, safety and development.

\section{Dyslexic and IT conference}

A new conference is going to take place in October 2003 to follow up on a conference held in 2001. The objective of the conference is also to create more political attention to the area and establish a forum for the target group, which will frequently be supplied with information of news in the area. The plan is to hold the conference every second year (Spring, in odd years).

\section{"Into Work"}

In the period 15-18 May 2003 the Danish Centre's NetJob department is going to hold the conference Into Work Conference 2003 in Athens. The conference puts focus on disability and the labour market. The conference is going to be a nice culmination of NetJob's large EU project SDV-NetJob. The conference is going to have two guests of honour: European Commissioner Ms. Anna Diamantopoulou and the Greek Minister for employment Mr. Michalis Reppas. Further more the chairman and managing director of European Disability Forum is going to participate as a speaker at the conference.

\section{$D K-D e A N$}

As EdeAN National Contact Centre the Danish Centre is also responsible for a national e-Accessibility network - DK-DeAN. The first meeting for the Danish network has been held on February 19. The focus of DK-DeAN is going to be providing European information and contacts of the area to and from Danish companies and organizations.

\section{Senior citizens and IT}

Manual for IT-education of senior citizens with disabilities. This book originates from a project under the Danish Research Agency's research programme Senior Citizens use of IT. This project primarily focused on senior citizens with disabilities as this group of people is often neglected at the traditional computer courses for senior citizens.

The objective of the project was to show how to take the disabilities of senior citizens into account, so they can be able to make use of the computer's possibilities and in that way participate on equal terms with other people in the information society. In the manual the experiences derived from the project are collected. The manual addresses teachers, educators, and therapists, who are occupied with senior citizens and IT, the senior citizens themselves and their relatives.

\section{Disability no obstacle}

The action plan from the Ministry of Science, Technology, and Innovation for disabled people's use of Information Technology and Telecommunication (IT\&T) 2002. The objective of the action plan is to insure disabled people's access to the network society. The plan of action for disabled people's use of IT\&T is going to lay down the way to an accessible network society in which people with disabilities do not experience the technology as an obstacle but as help.

\section{IT for All-Denmark's Future IT and Telecommunications Policy Statement and Action Plan 2002}

The aim of the Danish Government's IT\&T policy is to further economic growth and the reform of the public sector, and to contribute to equipping the nation for the knowledge society of the future. The IT Action Plan identifies seven key areas: 
- More IT in Danish business and industry

- A competitive telecommunications sector

- Strong IT competences in Denmark

- An IT-based public sector

- IT security

- Useful content on the Internet

- Danish influence on IT in the EU

The entire Action Plan can be found at www.videnskabsministeriet.dk/cgi-bin/theme-list.cgi?theme $\mathrm{jd}=$ 113672

\section{Spain}

\section{Cristina Rodríguez-Porrero ceapat@ceapat.org}

\section{White Book of R\&D\&i in Spain}

On April 9th, 2003, the White Book of $R \& D \& i$ for people with disabilities and older people (Libro blanco de la $I+D+i$ al servicio de las personas con discapacidad y de las personas mayores) will be presented in Madrid (Spain).

This book is the result of an ambitious project promoted by the National Centre for Personal Autonomy and Technical Aids (CEAPAT), under the National Institute for Migrations and Social Services (IMSERSO), and the Institute of Biomechanics of Valencia (IBV).

The objectives of the White Book are to:

a) Define the priority lines to be considered in the Spanish National Plan of R\&D, in the rehabilitation technologies sector

b) Encourage the cooperation between all the public institutions directly related with the exploitation of technological results

c) Increase social awareness about assistive technology, and

d) Stimulate the interest of economical and social groups associated with products and services for disabled people, in relation with the $R \& D$

The White Book was developed by a group of authors, with the support of a Consultative Group and the Coordination Committee, composed of various representatives of the relevant institutions in the disability sector, as well as research entities, professional and users' organizations.

- Chapter 1. Introduction and objectives

- Chapter 2. Introduction to the technologies for people with disabilities and older people

- Chapter 3. R\&D in the technological sector for people with disabilities and older people
- Chapters 4-13. Lacks and opportunities in the R\&D for the innovation in the following sectors:

* Assessment, treatment and rehabilitation techniques

* Technical aids for personal mobility, and orthoses and prostheses

* Technical aids for visual impairment

* Hearing prostheses

* Technical aids for information and communication

* Architectural and urbanistic accessibility

* Technical aids for daily living

* Access to private and public means of transport

* Furnishing

$*$ Accessibility to work places

- Chapter 14. Priority lines of R\&D and complementary measures

For further information: www.ceapat.org

\section{MEMBERS' NEWS}

\section{Research}

ICT is the Answer - But What is the Question? Jane Brodin jane.brodin@lhs.se

Parents of children with disabilities: their thoughts, experiences, \& expectations of Information \& Communication Technology.

Peg Lindstrand of the Disability and Handicap Research Group at the Stockholm Institute of Education has published a $\mathrm{PhD}$ dissertation that highlights the interaction between children with severe and multiple disabilities and assistive technology. The main focuses are parents' expectations, experiences and influence of Information and Communication Technology (ICT), and children with disabilities.

Five studies were conducted within three longitudinal projects. The results of these studies indicated that expectations contain a number of aspects. The central theme is the parents' sincere hope that their children will be able to participate actively in society and have the same opportunities as other children.

ICT creates floating borders that challenge a traditional way of looking at communication and relationships of power and established power relations can be questioned as a result of this. ICT thereby challenges a tradition of experts, in which the relationship between the client and the expert is organized according to a cer- 
tain order. Answers given by teachers and parents show that there is resistance among the institutions of society to see these floating borders as an advantage but parents have shown that we need to see the child's different life environments from a more holistic perspective.

The results concerning the school environment indicate that the communication between different levels in school organizations is insufficient. Software is seen as offering teaching aids for the individual, and the unique aspects of ICT that offer communication and inclusion possibilities are often forgotten. A conclusion is that the use of technology should be educationally managed rather than being managed by the technology itself.

The study concludes that ICT alone cannot solve any problems and that the key to progress is the pure human interest of all those concerned with the well-being of the children. The dissertation is available at Stockholm Institute of Education Press, Studies on Educational Sciences 60 (hls-forlag@lhs.se).

\section{FORTHCOMING EVENTS}

\section{DAISY Conference}

\section{Maarten Verboom MVerboom@fnb.nl}

This year's DAISY Conference will be held in Amsterdam on the 12th, 13th \& 14th of May 2003. The Daisy Consortium and FNB in the Netherlands are organising this conference. The conference theme is "DAISY For All".

The DAISY Consortium was born out of the global need for an international standard for Digital Talking Books. In less than six years, DAISY has become an accepted formal standard, and organizations and companies around the world are making the move to this standard - the standard for all navigable and accessible multimedia documents. The acronym DAISY denotes "Digital Accessible Information System".

Today in many countries the first services of providing Digital accessible documents to people with a print impairment are rolling out. These services vary: structured talking books, structured textbooks, 'hybrid' text and audio books, and multimedia documents. Also the group of people which is being served is broad and varied: visually impaired people, people with limited hand functions and have difficulties in handling print books or newspapers, people with learning disabilities.

At the Conference, you will find out why DAISY is THE "better way to read!". The theme of the conference is DAISY for All, and the Conference Program il- lustrates that this is a conference that will be of interest to everyone who is interested in providing accessible information to people with a print disability.

The DAISY Conference will cover the latest techniques, research results, workflow theory and best practices, marketing issues, exciting developments, new hardware and software, and much, much more.

To give an idea about what kind of presentations you can expect:

- Members of the Daisy Consortium will tell about their experiences and especially about their solutions.

- Daisy-players, which are designed for people with a print handicap, will be presented.

- Specific applications such multimedia players for people with learning disabilities are to be highlighted.

There will be workshops on several themes such as a dialogue between two strategies of making multimedia documents accessible, MultiReader and Daisy, and discussions on XML-techniques.

You can get additional information and details about the Conference web site: www.DAISY.org/events/ conf2003/.

\section{RESNA 26 International Conference Shannon Marullosmarullo@ resna.org}

\author{
Technology \& Disability: Research, Design, Practice \\ and Policy \\ June 19-23, 2003, Hyatt Regency, Atlanta, GA
}

The Annual RESNA conference this year adopts a new format, there being three conference tracks: Research, Practice, and Policy.

\section{AAATE 03 Conference (update) Gerald Craddock gcradd@ crc.ie}

The AAATE conference (August 31st - 3rd September $3 r d, 2003$ ) is coming to Ireland in an important year designated as the "European Year for People with Disabilities". It is the second event that Ireland has been honoured with in 2003, with the hosting of the "Special Olympics" in June. The AAATE conference will have the privilege of using the wonderful facilities prepared for these events to be held in our largest university, University College Dublin.

We have drawn together an equally exciting and international event, which we hope will excite new de- 
bate and discussion. It is a chance for us all to share our work and research, disseminate valuable information to people with disabilities and others. We will be offering over four days of papers, events and exhibitions, with a little bit of Irish "crac" and entertainment.

We are delighted with the response so far, with almost two hundred and fifty abstracts submitted from Europe, America, Australia and Japan. It is a daunting task to select from such outstanding work and encouraging that research within Assistive Technology is a thriving discipline today.

Our plenary program will include presentations in new technologies, standards, user-centred approaches, and interdisciplinary practices. Speakers include wellknown names within both the disability and assistive technology world. Chosen in recognition of their expertise, their presentations will further generate new debate and research in the constant effort to create a society, which is accessible to all.

Our speakers include:

Mr Adolf Ratzka, German disability activist and founder member of the Independent Living movement in Europe, now recognised as one of the leading catalysts of change within the disability movement today.

Dr. David B. Gray is an Associate Professor of Neurology and Ass.Professor of Occupational Therapy at Washington University School of Medicine in St Louis, Missouri. He teaches courses on assistive technology and disability policy and principal investigator on several research projects including the interactive, multimedia computer-based resource, "Accessing Your World". Dr. Gray has written book chapters and edited books related to AT including: Designing and Using Assistive Technology: The Human Perspective (1998). From 1986 to 1987 , Dr. Gray, was the Director of the National Institute on Disability and Rehabilitation Research (NIDRR) at the US Department of Education in Washington DC.

Dr Yvette Murin, representing CompTIA, the Computing Tech Industry Association has, for the past twenty years been dedicated to advancing the growth of the information technology (IT) industry and those working within it. With more than 13,000 members in 89 countries, CompTIA is the leading global IT trade association with influence in all areas of the IT industry worldwide.

Dr Gary McDarby from MediaLab Europe, the European Research Partner for MIT Media Lab and centre of a new Digital Hub in Ireland, will present the new and exciting work of his team. Working in partnership with Industry and Governmental organisations,
MediaLab Europe are leveraging the innovative and entrepreneurial operating model of the world-renowned MIT Media Lab to discover big and original ideas that transform the way we live and work. See further details in the Conference website at www.atireland.ie/aaate.

\section{ICOST'2003 - 1st International Conference On Smart Homes and Health Telematics Mounir Mokhtari Mounir.Mokhtari@int-evry.fr}

\author{
Independent living for persons with disabilities and \\ elderly people \\ 24-26 September 2003, Paris, France \\ www.int-evry.fr/handicom/icost 2003
}

\section{International Conference on Aging, Disability and Independence}

\section{Advancing Technology and Services to Promote Quality of Life \\ December 4-6, 2003, Washington, DC, USA}

This EU-US sponsored conference will bring together researchers, practitioners, business leaders, and people involved in aging policy to focus on these issues. The conference will include sessions related to research and development, practice, products and services and policies.

From Europe, session co-chairs include AAATE members Renzo Andrich and Crt Marincek, as well as Gunnar Fagerberg from the EC Unit, Elderly and Persons With Disabilities.

The abstract deadline is 18th of April; commissioned papers will be published following the conference and proceedings (abstracts and full papers) will be posted on the website of the Rehabilitation Engineering Research Center on Technology for Successful Aging www.rerc.ufl.edu.

The conference sponsors include the University of Florida Rehabilitation Engineering Research Center on Technology for Successful Aging, the American Society on Aging, and the European Commission.

The conference is financially supported by the National Institute on Disability and Rehabilitation Research, the Veterans Health Administration, private foundations and corporate sponsors. The conference program has been developed in cooperation with the European Commission.

Conference web site: www.asaging.org/icadi.

CVHI - Conference \& Workshop on Assistive Technologies for Vision \& Hearing Impairment: Stateof-the-Art \& New Challenges

Marion Hersh M.Hersh@elec.gla.ac.uk 


\section{9th June - 2nd July, 2004, Granada, Spain}

This is the third event in the new international conference series on Assistive Technologies and Rehabilitation Engineering supported by the European Commission. The Conference will take place 30th June 2nd July 2004 with Tutorial Workshops being held on Tuesday 29th June 2004 at the conference centre.

Support from the European Commission has enabled us to provide a number of bursaries for young researchers, which will cover the full cost of attendance at the conference. The deadline for application is $1 \mathrm{st}$ October 2003. To apply for a bursary either contact Ms V. Romanes or download the form from the website.

As with previous events in the series, the conference will have a residential communal atmosphere. The organisers intend the conference and conference materials to be fully accessible to all disabled researchers.

Conference website: www.elec.gla.ac.uk/Events _ page/CVHI.

\section{ICCHP 2004 - 9th International Conference on Computers Helping People with Special Needs Klaus Miesenberger Klaus.Miesenberger@jku.at}

The ICCHP conference (7-9 July 2004, Université Pierre et Marie Curie Paris, France) focuses upon all aspects of information, communication, and assistive technology for people with disabilities and elderly people.

ICCHP offers a unique platform for researchers, practitioners and experts to present and discuss their work on all aspects of information, communication and assistive technology for people with disabilities and elderly people.

Specialists are invited to organise, chair and publish Specific Thematic Sessions within the framework of the conference. Contributions will be published in SPRINGER Lecture Notes in Computer Science. www.springer.de/comp/lncs/index.html.

ICCHP wants to foster the transfer of know-how between research and practice and to increase the audience to the outstanding presentations. To avoid economic barriers the participation fee will be as low as possible.

Rooms and facilities for meetings of project and other consortia will be provided for free. Companies are invited to take part in a small exhibition and to give more intensive introductions in product workshops and seminars.

Deadline for abstracts: January 25, 2004

Conference web site: www.icchp.org

\section{ASSOCIATION MATTERS}

\section{AAATE networking / communication policy \\ Renzo Andrich renzo.andrich@siva.it}

In its first 2003 meeting held in Belluno, Italy, in January, the Board defined an overall policy for the AAATE networking and communication activities. This is described in a 10-page working document that any member interested can obtain from the Secretariat on request. Here a brief synthesis is provided.

First, a distinction is made between Internal and External networking / communication policy.

Internal NCP is addressed to AAATE Members, Board Members, Institutes taking part in the Forum. Main objectives are keeping informed about AAATE initiatives, exchange information, allow for access to AAATE documents, facilitate communication among members, help design AAATE initiatives, nurture the sense of being part of the association.

External NCP is addressed to the general public interested in assistive technology, to sister organisations (RESNA, ARATA, RESJA), to other organisations in contacts with AAATE, to EU Bodies, to national policy makers. Main objectives are presenting the Association, attracting members (by explaining why it is worth subscribing, and providing easy subscription procedures), advertising AAATE initiatives, express AAATE positions on relevant topics, promoting recognition of AAATE as the European AT Society.

The Tools for implementing the AAATE NCP are the:

- website (external and internal)

- newsletter (internal)

- Journal Technology and Disability (internal and external)

- Network of National Contacts (internal and external)

- Special Interest Groups (SIGs) (internal)

- Discussion List (internal)

- Cooperation Agreements with Sister Organisations (external)

- Representation in other Committees, Bodies or Events (external)

- Public relations material (external)

- Membership directory (internal)

- Membership outreach policy (internal and external)

For each such tool, the working document on NCP describes the purpose, the responsibilities involved, the implementation strategy, the current status. 


\section{OBITUARY}

\section{Jean-Claude Gabus}

\section{By Laurent Junier, President, FST}

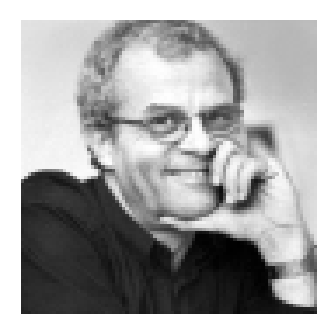

Jean-Claude Gabus died suddenly on March 18 from a heart attack while on a journey to Paris. He was director of the Fondation Suisse pour les Téléthèses (Swiss Foundation for Rehabilitation Technology).

For more than thirty years he had devoted his energy, creativity, generosity and engineering skills to serving the disabled and disadvantaged.

Jean-Claude spent his childhood in Le Locle. Where, already as a boy, he loved do-it-yourself and had only one interest: repairing damaged everyday objects. He liked to climb to the top of trees to look at the world from on high. In 1972, following some personal experiences that had profoundly affected him, he tried to meet the needs of people with communication disabilities with technological aids.

He was hired by the company Carba, where he put to use his first inventions and developed a line of communication aid products. The narrowness of the market and the emergence of microcomputers were to put an end to his job with Carba. In less than ten years he had gained recognition for the quality of his products by users, therapists, teachers, parents' associations and even by the Swiss Invalidity Insurance scheme. His fame already transcended Switzerland's borders.

It was at this point that he decided to continue his career in the same field. Under the auspices of the Swiss Foundation for children with cerebral motor disorders in Bern (Cerebral), the Foundation for paraplegics in Basle and with the support of the Federation of Migros cooperatives, he was behind the creation of the Fondation Suisse pour les Téléthèses (FST), which was established on December 16, 1982. His competency and spirit of enterprise and innovation were appreciated primarily by its users but also by its Swiss and foreign partners.

In 20 years more than 10,000 disabled people in Switzerland and 6,000 abroad benefited from the FST's services. Among the best-known and most striking innovations there was Hector (1984), the first apparatus to speak six languages and be programmable according to the user's requirements.

Next came James (1986), a revolutionary remote control capable of learning codes to facilitate the control of electronic devices and later on of allowing control of the environment in a wider sense. It was followed by Quo Vadis 1, an installation designed to prevent people subject to wandering (Alzheimer's disease sufferers, for example) from being confined to a restricted space.

Then came B.A.BAR in 2000 (an apparatus capable of reading bar codes and speaking with a digitalized voice), whose aim was to facilitate language learning and speech therapy and which opened up new prospects for the use of technical aids. Finally, Quo Vadis 2, which was installed at the psycho-geriatric cantonal hospital of Perreux.

The work of Jean-Claude would not have been possible without the assistance of his co-workers, to whom he listened constantly, seeking to make the best of each person's skills. He was also able to win the confidence and support of public and private organizations, both Swiss and foreign, without which the FST would not have been able to develop.

Jean-Claude was called upon to work as an expert to the European Commission. He always displayed a tireless spirit of creativity and a sense of human relations that put people before technology. His exceptional qualities earned him nine prestigious awards, including the l'Express prize and that of the Institut Neuchâtelois. Jean-Claude was always concerned about the FST's future, being aware of the vulnerability of its products in spite of their quality and originality. He leaves a life's work that was fully mature yet brimming with plans.

Jean-Claude Gabus was very aware of and grateful for the trust placed in him by the FST's users and partners. While Jean-Claude will evidently be irreplaceable, the Board of Foundation, along with the FST's management and co-workers, are committed to continuing their activities in the spirit of its founders and to developing further the reputed centre of competency that it has become under his stewardship.

Paula Brouillard (European commission) adds: "It is with a great sadness that we have learned the sudden death of Jean-Claude Gabus at the beginning of this week. Jean-Claude, as a leading figure in his Swiss foundation, had been involved in our RTD projects for many years, either as a direct participant or more recently as an independent expert assisting the Commission's services. 
Jean-Claude's enthusiasm and memory will stay with us in the domain of Assistive Technology and Design for All."

European Commission, Information Society Directorate-General Unit "Applications: Elderly and Persons with Disabilities"

\section{ADDRESS BOOK}

\section{AAATE Board Members}

Renzo Andrich, President

SIVA Fondazione Don Carlo Gnocchi Onlus

Milano, Italy

Phone +39024030 8444

Fax +390240090157

Email renzo.andrich@siva.it

Harry Knops, President Elect

IRV, Hoensbroek, The Netherlands

Phone +31 455237612

Fax +3145 5231550

Email h.knops@irv.nl

\section{Gerry Craddock}

Central Remedial Clinic

Ireland

\author{
Phone +35318057523 \\ Fax +35318335496 \\ Email gcraddock@crc.ie

\section{Jan Persson} \\ CMT University of Linköping, Sweden \\ Phone +4613224993 \\ Fax +4613224995 \\ Email jan.persson@ihs.liu.se
}

\section{Pier Luigi Emiliani}

Institute of Applied Physics

National Research Council

Florence, Italy

Phone +39055 4235300

Fax +39055 4235286

Email p.l.emiliani@ifac.cnr.it

\section{Erland Winterberg}

Danish Centre, Taastrup, Denmark,

Phone +45 43993322

Fax +45 42527072

Email e.winterberg@hmi.dk

\section{AAATE Office}

C/o Danish Centre, Taastrup, Denmark Phone +45 43993322

Fax +45 42527072

Email aaate@hmi.dk 
AAATE National Contacts

\begin{tabular}{llll}
\hline Country & Name & E-mail address & Affiliation \\
\hline Austria & Wolfgang Zagler & zw@fortec.tuwien.ac.at & FORTEC Tech Univ Vienna \\
Brazil & Maria Goncalves & mjesus@alpha.hydra.com.br & \\
Denmark & Niels-Erik Mathiassen & ne.mathiassen@hmi.dk & Danish Centre \\
Finland & Jan Ekberg & Jan.Ekberg@stakes.fi & STAKES. \\
France & Alain Pruski & alain.pruski@lasc.univ-metz.fr & University of Metz. \\
Germany & Christian Bühler & cb@ftb-volmarstein.de & FTB \\
Greece & Constantine Stephanidis & cs@csi.forth.gr & ICS-FORTH. \\
Hungary & Andras Arato & arato@sunserv.kfki.hu & Lab.Speech Technology at KFKI \\
Ireland & Gerald Craddock & gcradd@crc.ie & Central Remedial Clinic. \\
Israel & Lawrence Normie & lnormie@jdc.org.il & GeronTech Israeli Ct AT \& Aging \\
Italy & Renzo Andrich & renzo.andrich@siva.it & SIVA Fond. Don Gnocchi Onlus \\
Netherlands & Harry Knops & h.knops@irv.nl & iRv \\
Norway & Oivind Lorentsen & oivind.lorentsen@ online.no & Rehab-Nor \\
Portugal & Luis Azevedo & pclma@alfa.ist.utl.pt & CAPS Tech Univ Lisbon \\
Slovakia & Dusan Simsik & Dusan.Simsik@tuke.sk & Tech Univ Košice \\
Slovenia & Crt Marincek & crt.marincek@mail.ir-rs.si & Univ Institute for Rehabilitation \\
Spain & Cristina R. Porrero & crodriguez@mtas.es & CEAPAT \\
Sweden & Hakan Neveryd & hakan.neveryd@certec.lth.se & CERTEC, Lund University \\
UK & Nick Hine & nhine@computing.dundee.ac.uk & Dept Computing Univ. Dundee \\
\hline
\end{tabular}

